\title{
TRAINING IN INNOVATIVE TECHNOLOGIES FOR CLOSE-RANGE SENSING IN ALPINE TERRAIN - $3^{\text {rd }}$ EDITION
}

\author{
M. Rutzinger ${ }^{1,2}$, K. Anders ${ }^{3}$, M. Bremer ${ }^{1,2}$, B. Höfle ${ }^{3}$, R., Lindenbergh ${ }^{4}$, S. Oude Elberink ${ }^{5}$, F. Pirotti ${ }^{6}$, M. Scaioni ${ }^{7,8}$, T. Zieher ${ }^{1,2}$ \\ ${ }^{1}$ Institute for Interdisciplinary Mountain Research, Austrian Academy of Sciences, Austria - martin.rutzinger, magnus.bremer, \\ thomas.zieher@oeaw.ac.at \\ ${ }^{2}$ Institute of Geography, University of Innsbruck, Austria - martin.rutzinger, magnus.bremer, thomas.zieher@uibk.ac.at \\ ${ }^{3}$ GIScience, Institute of Geography, Heidelberg University, Germany - hoefle, katharina.anders@uni-heidelberg.de \\ ${ }^{4}$ Dept. of Geoscience \& Remote Sensing, Delft University of Technology, The Netherlands - r.c.lindenbergh@tudelft.nl \\ ${ }^{5}$ ITC - Faculty of Geo-Information Sciences and Earth Observation, University of Twente, The Netherlands - \\ s.j.oudeelberink@utwente.nl \\ ${ }^{6}$ Interdepartmental Research Center of Geomatics (CIRGEO), University of Padova - francesco.pirotti@unipd.it \\ ${ }^{7}$ Department of Architecture, Build Environment and Construction Engineering, Politecnico di Milano, Italy - \\ marco.scaioni@polimi.it \\ ${ }^{8}$ College of Surveying and Geo-Informatics, Tongji University, Shanghai, P.R. China - marco@tongji.edu.cn
}

\section{Commission II, WG II/10}

KEY WORDS: knowledge transfer, $\mathrm{PhD}$ education summer school, mountain research, natural hazards, vegetation mapping, glaciology, terrestrial laser scanning, close-range photogrammetry, thermography, multi-temporal 3D point cloud analysis

\begin{abstract}
:
The $3^{\text {rd }}$ edition of the international summer school "Close-range Sensing Techniques in Alpine terrain" took place in Obergurgl, Austria, in June 2019. This article reports on results from the training and seminar activities and the outcome of student questionnaire survey. Comparison between the recent edition and the past edition in 2017 shows no significant differences on the level of satisfaction on organizational and training aspects. Gender balance was present both in candidates and in the outcome of selections. Selection was based on past research activities and on topic relevance. The majority of trainees were therefore doctoral candidates and postdoctoral researchers, but also motivated master students participated. The training took place through keynotes, lectures, seminars, in the field with hands-on surveys followed by data analysis in the lab, and teamwork for preparing a final team presentation over different assignments.
\end{abstract}

\section{INTRODUCTION}

The international Innsbruck Summer School of Alpine Research - Close-range Techniques in Alpine Terrain hosts full five days of theoretical and practical training. The location provides real examples of Earth surface phenomena related to mountain research such as natural hazards, diverse vegetation, permafrost and snow/ice interaction in mountain terrain. The recent edition in 2019 is compared with the past editions in 2015 and especially 2017 in terms of development of assignments and organization (Rutzinger et al., 2018, 2016).

\section{MATERIALS AND METHODS}

\subsection{Involved researchers}

The organisation committee consists of eight researchers from academic affiliations in Austria, Germany, The Netherlands, and Italy. Other staff include invited reserachers for keynote speeches, assignment support and other activities that help in training. Keynote speakers are experts in geomatics and earth observation, laser scanning, photogrammetry and natural hazard management. Support came from staff of the organisation committee and other participants that helped with the documentation of the summer school, organisation of assignments and surveys with sensors.

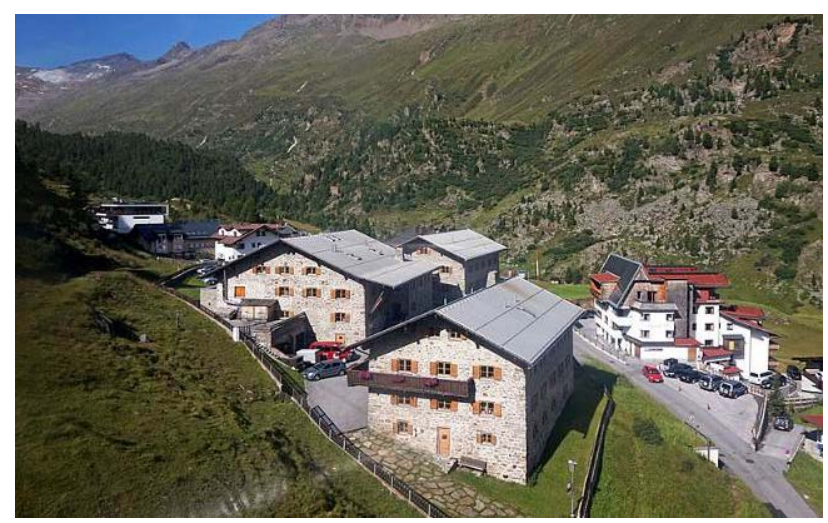

Figure 1. Location of the summer school venue University Centre Obergurgl (Austria) (Tina Monto CC BY-SA 3.0).

\subsection{Candidate selection}

Candidates were selected from incoming requests to participate after some months of promoting the summer school through mailing lists, online calendars, flyers and over a strong international network. Being the third edition, also informal promotion was done by past participants and by involved staff. The promotion effort led to 75 submitted requests from 28 different countries (Table 1). 
Table 1. Country distribution of applicants.

\begin{tabular}{llllll} 
Country & N. & Country & N. & Country & N. \\
\hline Italy & 12 & Pakistan & 2 & Israel & 1 \\
Germany & 9 & US & 2 & Luxembourg & 1 \\
Austria & 5 & Brazil & 1 & Malaysia & 1 \\
Netherlands & 6 & Canada & 1 & Morocco & 1 \\
UK & 5 & China & 1 & Serbia & 1 \\
France & 4 & Denmark & 1 & Slovakia & 1 \\
India & 4 & Greece & 1 & Slovenia & 1 \\
Switzerland & 4 & Hungary & 1 & Sweden & 1 \\
Belgium & 3 & Indonesia & 1 & USA & 1 \\
Norway & 3 & & & TOTAL & $\mathbf{7 5}$
\end{tabular}

Participants were selected by independently assigning weights to academic curriculum, motivation letter, number of publications and impact of journals. Different weight was given to the degree held by the candidate to support applications from $\mathrm{PhD}$ candidates and postdocs. Three members of the organising committee reviewed the proposals providing weights for each criterion to each candidate. The average from the three votes gave the final ranking from which the forty final participants were selected.

\subsection{Keynotes}

The summer school has been supported by six keynotes on technical and scientific topics, which were "Past, Current and Future Developments in Photogrammetry" by Fabio Remondino (3D Optical Metrology, Fondazione Bruno Kessler, Italy), "Laser Scanning and Challenges in Alpine Research" by Norbert Pfeifer (Department of Geodesy and Geoinformation, TU Vienna, Austria), "Biogeomorphology in the Anthropocene" by Heather Viles (School of Geography and the Environment, University of Oxford, United Kingdom), "Addressing Biophysical Feedbacks to Climate at Small Spatial Scales - the EcoBot Concept" by Georg Wohlfahrt (Institute of Ecology, University of Innsbruck, Austria), "Combining Remote Sensing and Geoscience Data as the Framework for Virtual Field Trips" by Simon John Buckley (NORCE Norwegian Research Centre, Norway) and "ICECUBES Observing the Ice of our Planet with Daily CubeSat Imagery" by Bas Altena (Department of Geosciences, University of Oslo, Norway). Keynote speakers stayed one to several days at the venue being available for deepening scientific discussions with participants.

\subsection{Training rationale}

Participants had the possibility to get familiar with processing methods by conducting an online course before the summer school, which has been developed by the ISPRS Education and Capacity Building Initiative funded project Spreading out the Knowledge from ISPRS Educational Events using a Dissemination Internet Platform (SKIEE-DIP). Sample data sets have been published open access (Pfeiffer et al. 2019a, Pfeiffer et al. 2019b, Pfeiffer et al. 2019c).

The summer school also provided time for participants presenting their own research as poster presentation in a dedicated session. A proceedings booklet has been published under open access licence comprising abstracts from participants, lectures and keynotes (Rutzinger \& Heinrich 2019).

Assignments aim at the design, conduction, analysis and presentation of a close-range sensing measurement campaign in a mountain environment. Small groups of participants conducted assignments dealing with a specific sensor and mountain research problem (Tab. 2).

\begin{tabular}{ll} 
Table 2. Assignment topics \\
\hline \multicolumn{2}{l}{ Assignments } \\
\hline 1 & Thermographic and Photogrammetric Analysis of an Alpine Snow \\
& Patch \\
2 & Detection of Geomorphic Activity using Topographic LiDAR \\
3 & Terrestrial Laser Scanning Time Series based Classification \\
4 & Terrestrial Photogrammetry for Rockfall Mapping and Monitoring \\
5 & Terrestrial Near Infrared Photogrammetry for Classification using \\
& Machine Learning \\
6 & UAV Photogrammetry for Detecting Fluvial Channel Erosion \\
7 & Quantification of Landslide-induced Topographic Changes using \\
& Terrestrial Laser Scanning \\
\hline
\end{tabular}

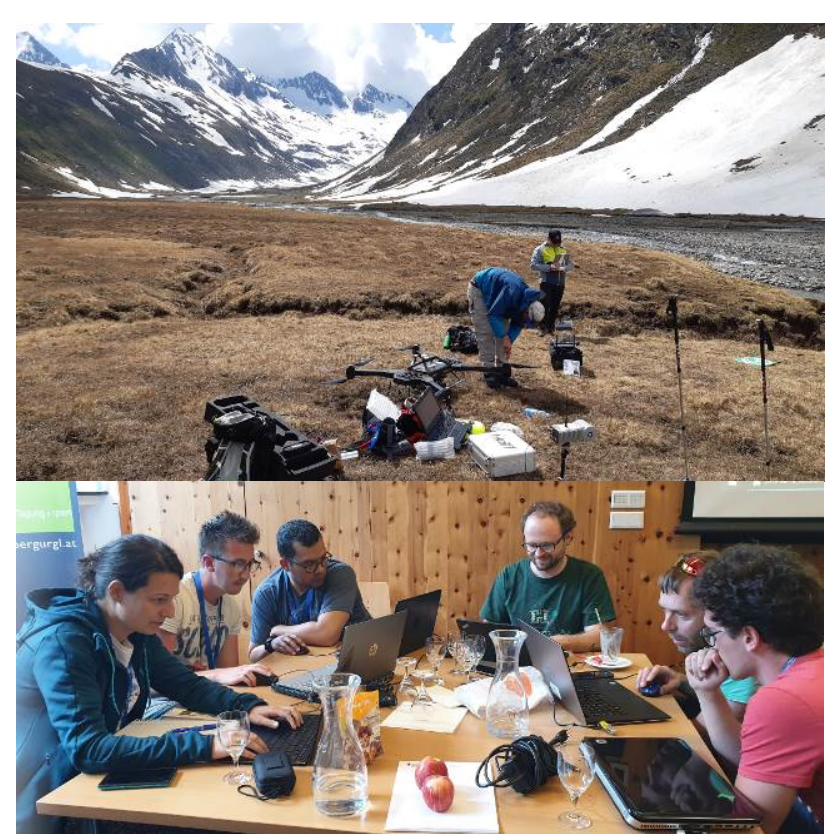

Figure 2. For assignments all sensors and platforms have to be carried to the field site of interest (top), sensors on hand-held, terrestrial and UAV-platforms have been studied (top) and finally data has been processed and analysed by participants (bottom).

Assignment 1: Thermographic and Photogrammetric Analysis of an Alpine Snow Patch observed the melting phase of a snow pack over four hours by terrestrial thermography using an InfraTech VarioCam ${ }^{\circledR}$ high resolution camera (Fig. 3) and reference measurements using Thermochrone iButtons. Volume changes have been estimated based on 3D models generated by terrestrial photogrammetry. Finally, conducting 3D photogrammetry using thermal imagery directly has been tested in an experiment. 


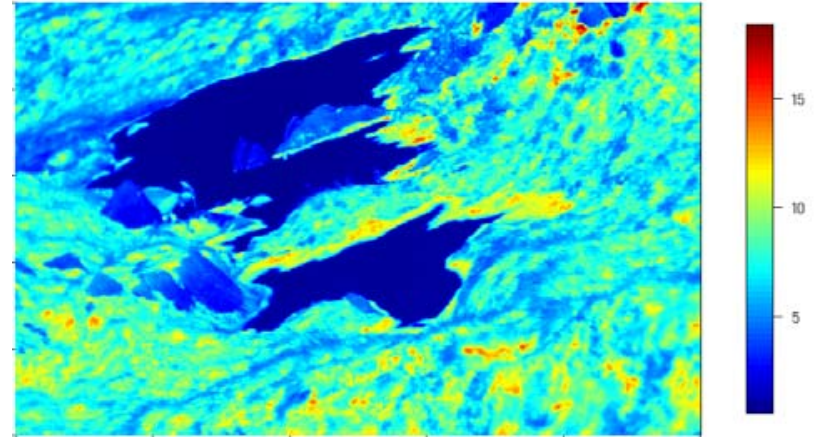

Figure 3: Standard deviation of radiation temperature $\left[{ }^{\circ} \mathrm{C}\right]$ measured at a snow patch during a period of $4 \mathrm{~h}$ in $5 \mathrm{~min}$ intervals.

Assignment 2: Detection of Geomorphic Activity using Topographic LiDAR covers the analysis of multitemporal 3D point clouds for geomorphic process detection. The objective is to quantify short- and long-term surface change on an active geomorphic phenomenon via the analysis of multitemporal point clouds acquired with terrestrial laser scanning (TLS). The resulting surface change information is used for interpretation of geomorphic activity. The study object is the Zirbenwald rockfall on the orographic left side of the Gurgler Ache river. The rockfall has a distinct headwall and talus in form of a debris cone beneath (Fig. 4). The rockfall was acquired with a Riegl VZ-400 TLS in 2015 (Rutzinger et al., 2016). The acquisition from the same scan positions was repeated twice in 2019 on two consecutive days, respectively, with a Riegl VZ-2000i TLS. By this, two time scales of multitemporal point clouds of a four-year and one-day period can be analysed.

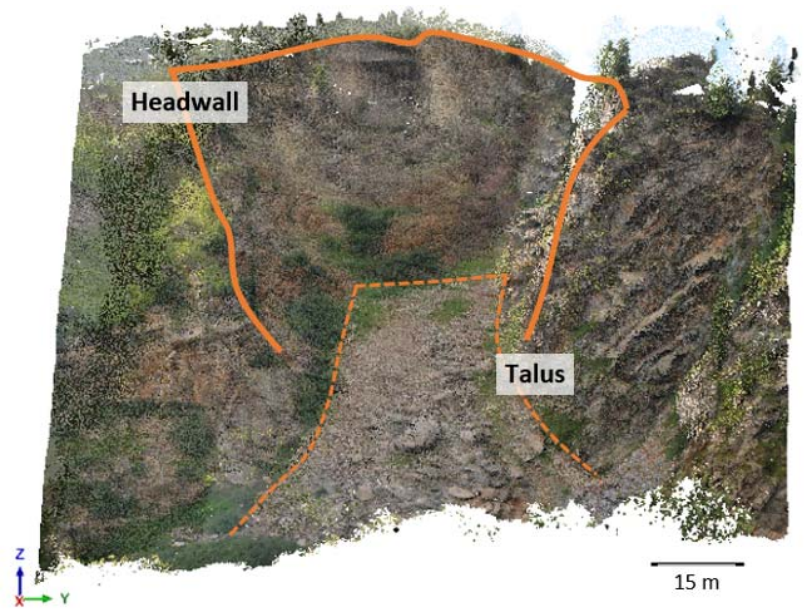

Figure 4. TLS point cloud of Zirbenwald rockfall acquired in July 2015, coloured by RGB. Headwall and talus are schematically delineated.

The point clouds are co-registered in a common reference frame and georeferenced using RTK GNSS measurements. Surface change is quantified as point cloud distances using the $\mathrm{M} 3 \mathrm{C} 2$ algorithm (Lague et al., 2013). Tracking of individual boulder movement was examined visually in hillshade rasters of Digital Elevation Models (DEMs) of each epoch. Further, the laser backscatter values are investigated for a relation to changes on the rockfall. Since no observable changes occurred in the twoday period, the analysis focuses on the four-year period.

Several trees that are present at the edge of the headwall disappeared within the four years of observation and hence presumably fell off with the eroding headwall. A positive surface change of around $8.5 \mathrm{~cm}$ has been found in the area of the headwall, which could indicate a forward tilt towards the rockfall. The overall talus slope appears to be mostly stable from the point cloud distance calculation. Manual tracking of individual boulders confirms that many parts of the rockfall talus are stable even on the scale of small, individual boulders. Some medium-sized $(<0.3 \mathrm{~m}$ ) and large (up to $5.0 \mathrm{~m}$ ) boulders are found to be displaced by $0.4-0.6 \mathrm{~m}$ and $0.5-1.5 \mathrm{~m}$, respectively. Visible differences in TLS backscatter are found for areas that geometrically changed on the headwall, which can be explained by a changed incidence angle on the eroded area that is missing a boulder-shaped piece. From the given data, no relation to different states of weathering is apparent between the previously and newly exposed rock surface.

Assignment 3: Terrestrial Laser Scanning time series-based classification. This assignment is strongly experimental as it exploits, for the first time as far as we know, the use of instantaneous motion in repeated scan data to differentiate between object types. TLS generally refers to the use of a panoramic scanner mounted on a tripod, compare the measurement setup in Figure 5. In outdoor scenes, vegetation and similarly flexible objects are moved by wind, resulting in noisy and geometrically disturbed data, which may affect a change detection analysis (Lindenbergh et al., 2015). In recent years, some permanent or continuous TLS setups were used, in which a panoramic scanner is scanning the same scene over and over again from the same standpoint, at, say, hourly intervals, to assess for example rockfalls, glacial change or gradual change at sandy beaches (Vos et al., 2017).

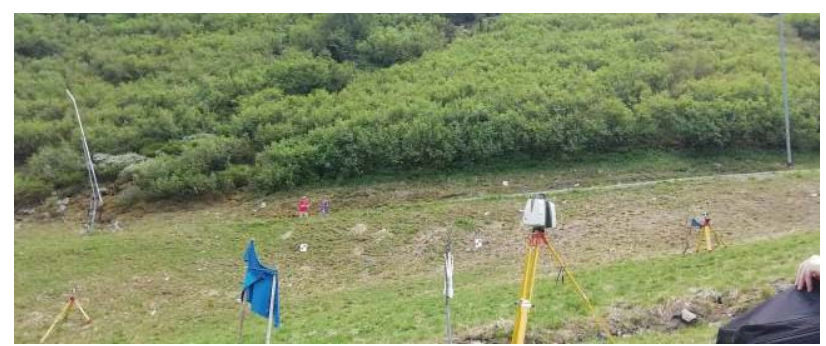

Figure 5. Scan location at Rumsoppen of the time series-based classification assignment. The location in the image is scanned 11 times at $10^{\prime}$ interval. Trees and a piece of cloth are expected to be moved by wind.

Inspired by permanent laser scanning research, this assignment aims at classifying $3 \mathrm{D}$ points in an outdoor scene by analysing their temporal range consistency in a series of 11 consecutive scans, obtained by a Leica P40, using its so-called wake-up mode. The scans with the same horizontal field of view of $110^{\circ}$ and a $6 \mathrm{~mm}$ at $100 \mathrm{~m}$ resolution, were obtained at 10' intervals from the same standpoint, observing basically the same scene, compare Figure 5. In this scene, wind is expected to move shrubs, trees and a jacket, attached between two sticks. In addition, passers-by will cause variations between scans. Wind speed data from during the experiment was available from the nearby $(\sim 200 \mathrm{~m})$ Obergurgl weather station, and is visualized by green dots in Figure 6 . From the graph it can be seen that wind speed is picking up during the experiment.

To process the scan data, first its temporal stability was assessed using artificial targets, placed in the scene for that purpose. Target stability was, as expected, at millimetre level. To assess changes between repeated scans, the cloud to cloud distance can be used. Given the fixed set-up, it is efficient to assess this in a range image organization of the scan data, in which the scanner coordinates are organized in a spherical 
coordinate system, centred at the scan location (Lindenbergh et al., 2015). Initial maximal displacements relative to a reference scan obtained at low wind speed, indicate correlation between displacement and wind speed, compare the blue bars in Figure 6. Full evaluation of the experiment data during the summer school appeared challenging, but initial results indicate that it may even be possible to assess the wind speed from displacements observed during the experiments, compare the orange graph in Figure 6.

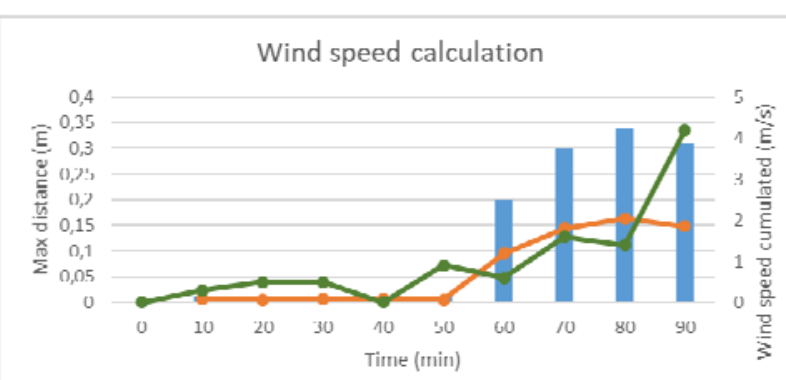

Mox distance displacement (m) $\rightarrow$ LLDAR Wind velocity (m/s)

$\rightarrow$ Obergulgl station wind specd $(\mathrm{m} / \mathrm{s})$

Figure 6. Wind regime near the scan location (green graph) compared to the maximal displacement w.r.t. a reference epoch (blue graph). Larger wind speeds near the end of the experiment correspond to larger displacements in the scan data.

Assignment 4: Terrestrial Photogrammetry for Rockfall Mapping and Monitoring. The first goal was to find an optimal way to capture and process terrestrial image data of a rockfall in a complex Alpine environment. The second goal was to detect changes between data sets from 2017 and 2019, and understand which portion of the differences in both datasets relate to rockfall changes. For the latter goal, it was important to characterize the rockfall by detecting the most important geological features.
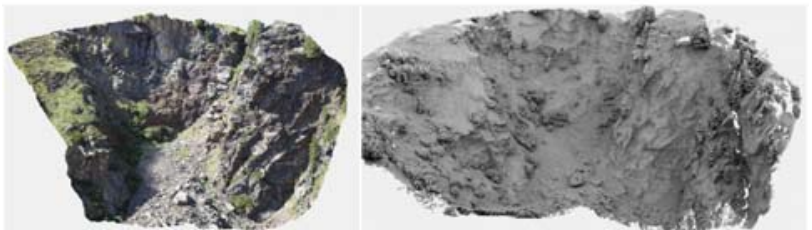

Figure 7. Image based point cloud (left) and TLS point cloud (right) of Zirbenwald rockfall.

The rockfall site covers about $5.000 \mathrm{~m}^{2}$, featuring rock blocks, low vegetation and cliffs. Due to the complexity of the site, the image configuration was limited in terms of accessibility and angle between sensor and object. The first set of images were taken about $100 \mathrm{~m}$ away from the rockfall, using a $24 \mathrm{~mm}$ focal-length configuration, the second set with a $105 \mathrm{~mm}$ configuration focussing on the upper part of the site. This site was also captured with a Riegl VZ-2000i TLS, with an average point spacing of $3 \mathrm{~cm}$ from approximately the same positions as the images, albeit on only 3 scan positions. Image point clouds were generated using OpenMVS and Photoscan, which gave comparable results between the software packages. The image based point clouds which were generated with a $105 \mathrm{~mm}$ configuration were comparable to the laser scanner dataset in terms of point density and point noise.

Assignment 5: Terrestrial Near Infrared Photogrammetry for Classification using Machine Learning. aimed at using terrestrial photogrammetry, structure from motion, dense image matching and machine learning to extract and classify a 3D point cloud of an area with different surface types (e.g. peat, rocks, vegetation, moss, snow). A NIKON D80 camera modified by removing the infrared-blocking internal filter was used. The camera sensor therefore mixed incoming radiance from both the visible and near infrared (NIR) area of the electromagnetic spectrum (Fredembach and Süsstrunk, 2008). A cut-filter (HOYA R72) for removing incoming light below $\lambda=720 \mathrm{~nm}$ allows to combine images taken with and without the filter for combining effectively NIR and providing blue, green, red and NIR information. These spectral features are integrated with geometric features calculated with respect to neighbouring points, e.g. planarity, sphericity, entropy, etc. using CloudCompare v2.11. The feature vectors with spectral and geometric properties of points representative of each class are used for training and validation in a classification process (Fig. 8). Classification is done with random forest, a machine learning method that has provided positive results in point cloud classification (Pirotti and Tonion, 2019). Trainees finally calculated accuracy metrics from cross-validation techniques (Pirotti et al., 2017).

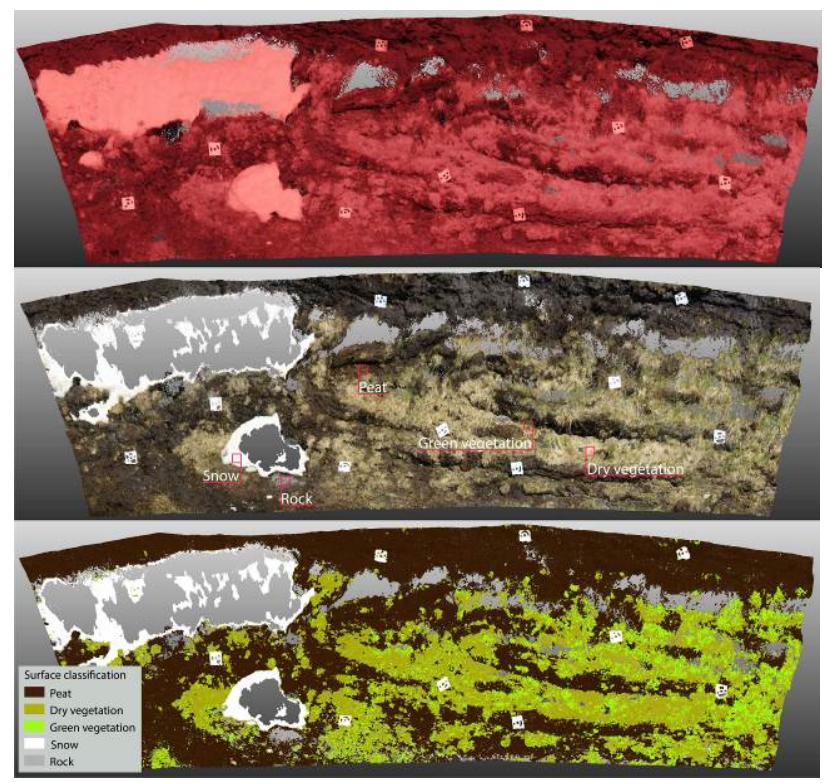

Figure 8 . Input imagery and classification result.

Assignment 6: UAV Photogrammetry for Detecting Fluvial Channel Erosion was conducted in the Rootmos Valley $(46.845 \mathrm{E}, 11.019 \mathrm{~N})$, where two point clouds based on UAVPhotogrammetry were available from previous summer schools (2015, 2017). A new data set was collected with a DJI Phantom 4 Pro at flying heights of $80 \mathrm{~m}$ and $100 \mathrm{~m}$. Twelve coded targets were used as GCPs. Concurrently, an Unmanned Laser Scanning (ULS) data set was acquired using a RIEGL RiCOPTER equipped with a VUX-1LR laser scanner and an Applanix AP20 IMU/DGNSS unit. The dense point clouds derived from Dense Image Matching for the three investigated epochs were registered by means of ICP algorithm, which was performed on stable grassland area next to the riverbed. A comparison between different epochs was carried out using M3C2 algorithm (Lague et al. 2013) implemented in CloudCompare software. This analysis allowed to identify areas of erosion and accumulation and their temporal variability within the riverbed. 
Assignment 7: Quantification of landslide-induced topographic changes using Terrestrial Laser Scanning aimed at quantifying area-wide topographic change at an active landslide site based on the analysis of multi-temporal LiDAR point clouds and their derivatives. Topographic changes of the past were first analysed using existing ALS and TLS data. This time series was then expanded with a Riegl VZ-6000 long-range TLS scan, designed and evaluated by the students, to derive changes of the terrain, which have occurred since the last TLS acquisition in 2017. A processing workflow had to be elaborated for extracting a DTM, which was then compared to those of past acquisitions. The workflow comprised (i) re-analysis of topographic changes based on existing data, (ii) planning of a TLS acquisition campaign with multiple scanning positions, (iii) acquisition of TLS point clouds, documentation of data acquisition, (iv) point cloud pre-processing: coarse and fine registration, georeferencing, (v) point cloud processing: outlier filtering, ground classification, (vi) uncertainty estimation of the acquired data for change detection, (vii) quantification of topographic change based on multi-temporal point clouds.

For the processing workflow the open source software packages CloudCompare, SAGA GIS, Python 2.7 and the R statistics were used. Particular attention was paid to the ground classification where three different morphological filtering techniques were systematically tested, including the progressive TIN densification filter (Axelsson, 2000), the cloth simulation filter (CSF, Zhang et al. 2016) and the multiscale curvature classification algorithm (MCC-LiDAR, Evans and Hudak, 2007). The resulting fraction of classified ground points of the systematic parameter tests with the applied techniques were compared (Figure 9). The results indicate, that the applied techniques show large differences with regard to their parameter sensitivity and the yielded fraction of ground points. The final results allow a geomorphological interpretation of the landslide's activity, including the quantification of the displaced and accumulated material.
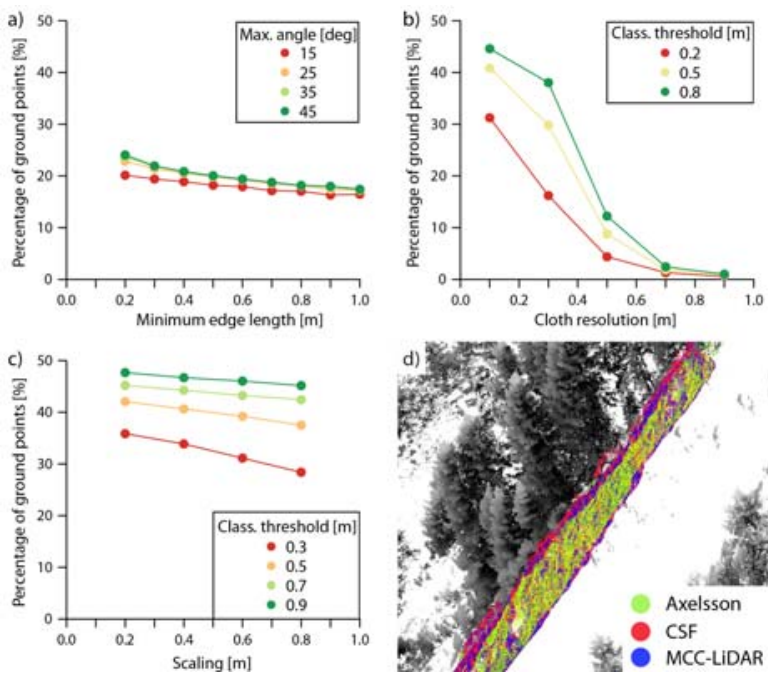

Figure 9. Results of the parameter tests using the Axelsson filter (progressive TIN densification, a), the cloth simulation filter (CSF, b) and the MCC-LiDAR algorithm (c) and a comparison of the results along a profile (d).

\section{RESULTS AND DISCUSSION}

\subsection{Participants}

Trainees in the summer school were selected from the 75 candidates as reported in Section 2.3. This year the 40 selected participants are affiliated to 34 institutions (Table 3) from 16 countries (Figure 10). This is an increase with respect to the previous edition in 2017 when 29 different institutions were represented. In both editions most participants were younger than 30 years old and $\mathrm{PhD}$ students at time of training (Fig. 11).

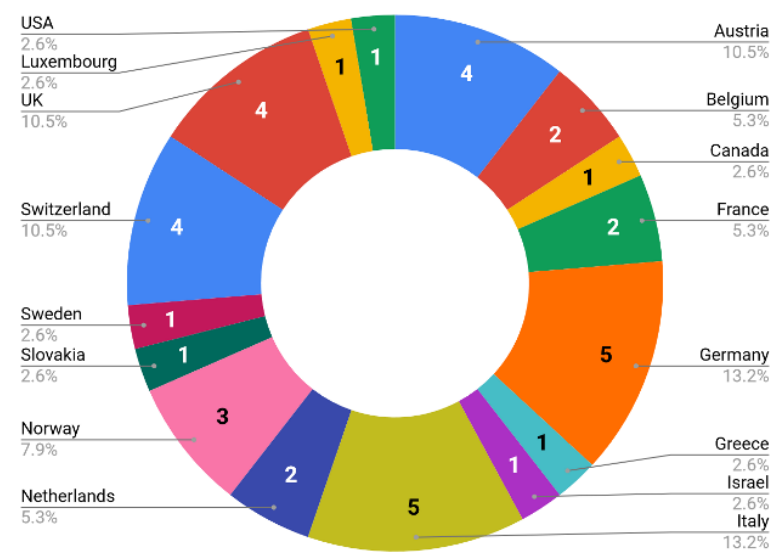

Figure 10. Internationality of participants.

Table 3. Affiliations of participants

\section{Arctic University of Tromsø (Norway)}

2 Aristotle University of Thessaloniki (Greece)

3 Delft University of Technology (Netherlands)

$4 \quad$ ETH Zurich (Switzerland)

5 FAU Erlangen-Nürnberg (Germany)

6 FBK Trento (Italy)

7 Ghent University (Belgium)

8 Heidelberg University (Germany)

9 Leopold-Franzens-University Innsbruck (Austria)

10 Newcastle University (UK)

11 Polytechnic of Bari (Italy)

12 Rheinische Friedrich-Wilhelms-Universität Bonn (Germany)

13 Royal Hollaway University of London (UK)

14 Stockholms University (Sweden)

15 Technical University Darmstadt (Germany)

16 Technical University in Zvolen (Slovakia)

17 Technion - Israel Institute of Technology (Israel)

18 Università degli studi dell'Insubria, Como/Varese (Italy)

19 Université de Savoie (France)

20 Université Grenoble Alpes (France)

21 Universitetet i Stavanger (Norway)

22 University of Basel (Switzerland)

23 University of Bern (Switzerland)

24 University of Luxembourg

25 University of Manchester (UK)

26 University of Maryland (USA)

27 University of Padua (Italy)

28 University of Salzburg (Austria)

29 University of South-Eastern Norway (Norway)

30 University of St Andrews (UK)

31 University of Victoria (Canada)

32 University of Vienna (Austria)

33 Vrije Universiteit Brussel (Belgium)

34 WSL - Institute for Snow and Avalanche Research SLF (Switzerland) 


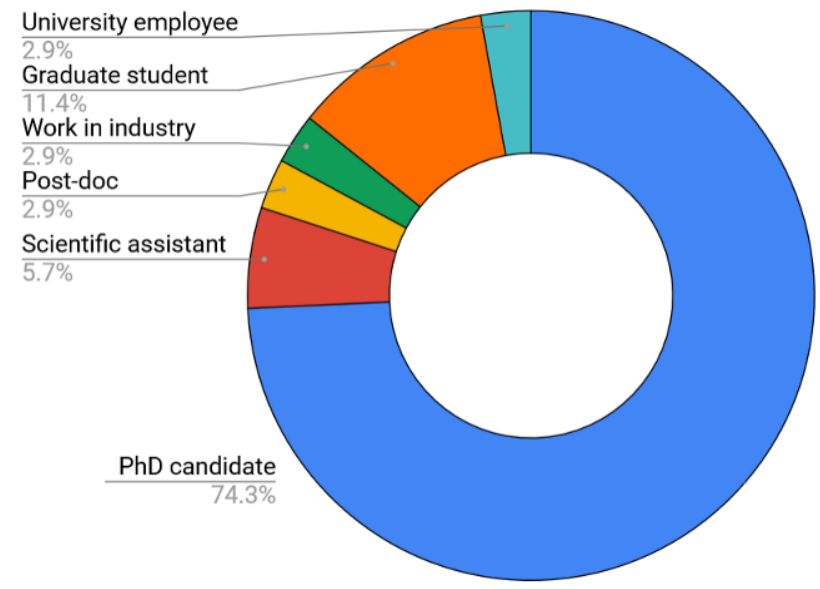

Figure 11. Frequency distribution of trainee positions at time of training

\subsection{Feedback from participants}

To improve the future courses and assess the work done with respect to satisfaction of trainees, an online form was sent to each participant when the summer school was finished, which could be filled our anonymously. Three sections separate the questionnaire into question types (i) related to organizational aspects, (ii) on how participants learned about the summer school and (iii) related to didactics and assignments. In Table 4 the list of questions is reported. Some questions required answers according to an ordinal scale of 1 to 10 , with 10 being the most favourable answer; these are marked with an asterisk in Table 4. Other answers had a nominal scale with predefined classes. With respect to the past edition, one more question was added related to the online course, to which students had access to before, during and after the summer school. $92 \%$ of scholars (35 out of 38) participated in the questionnaire with an improvement of $66 \%$ compared to the previous edition's ( 25 out of 38) response ratio, possibly indicating more involvement from students and also experience from previous editions which indicated that for a better turnout the organizers have to explicitly solicit participants to fill in the questionnaire on the last day of the event (Rutzinger et al., 2018).

Table 4. Questions in feedback form. Values for column "N." are enumerated (1-11) with asterisk for ordinal scale answers, or letters (A-D) for nominal scale and remaining (E-I) for free text answers.

\begin{tabular}{|c|c|}
\hline N. & Organizational questions \\
\hline $1 *$ & Is the location of the summer school appropriate? \\
\hline 2* & $\begin{array}{l}\text { Are the facilities and services appropriate? (rooms, meals } \\
\text { etc...) }\end{array}$ \\
\hline 3* & $\begin{array}{l}\text { Please rate the overall schedule (time for talks, field } \\
\text { work, data processing, free time) }\end{array}$ \\
\hline $\mathbf{A}$ & How did you learn about this summer school? \\
\hline \multirow[t]{2}{*}{ B } & $\begin{array}{l}\text { If you were planning the next summer school, how } \\
\text { would you adjust the schedule? }\end{array}$ \\
\hline & Assignment questions \\
\hline $\mathbf{C}$ & What assignment did you follow? \\
\hline $\mathbf{D}$ & What assignment was your first choice? \\
\hline $4 *$ & $\begin{array}{l}\text { Was the topic and goal of the assignment clearly } \\
\text { defined? }\end{array}$ \\
\hline $5 *$ & Was the schedule of time dedicated to assignment and \\
\hline
\end{tabular}

\begin{tabular}{|c|c|}
\hline & fieldwork respected? \\
\hline $6^{*}$ & Was the ratio of lectures/field-work/demos ideal? \\
\hline $7 *$ & $\begin{array}{l}\text { Did the assignment reflect what you expected in terms of } \\
\text { contents? }\end{array}$ \\
\hline 8* $^{*}$ & $\begin{array}{l}\text { Independently from your expectations, did the } \\
\text { assignment add value to your knowledge-base? }\end{array}$ \\
\hline 9* & Was the workload appropriate? \\
\hline $10 *$ & $\begin{array}{l}\text { How do you rate the idea of writing the assignment } \\
\text { report in the pre-defined ISPRS conference paper } \\
\text { template? }\end{array}$ \\
\hline 11* & $\begin{array}{l}\text { Please provide a self-assessment of your motivation to } \\
\text { polish your initial analyses beyond the summer school to } \\
\text { finally produce a scientific publication }\end{array}$ \\
\hline $\mathbf{E}$ & $\begin{array}{l}\text { For what reasons would you recommend your colleagues } \\
\text { to attend this course unit? Please indicate what aspects } \\
\text { you consider to be positive, satisfying or important. }\end{array}$ \\
\hline $\mathbf{F}$ & $\begin{array}{l}\text { For what reasons would you not recommend your } \\
\text { colleagues to attend this course unit? Please indicate } \\
\text { what aspects are critical, unsatisfactory, unnecessary or } \\
\text { disappointing }\end{array}$ \\
\hline $\mathbf{G}$ & Please add your suggestions for improvements. \\
\hline $\mathbf{H}$ & $\begin{array}{l}\text { Add suggestions on how the interaction between } \\
\text { participants and between participants and lecturers could } \\
\text { be further improved. }\end{array}$ \\
\hline I & $\begin{array}{l}\text { Please comment on the ONLINE COURSE of the } \\
\text { summer school. Which exercise did you do? Where do } \\
\text { you see room for improvement? }\end{array}$ \\
\hline
\end{tabular}

3.2.1 Questions 1-11: possible statistics for ordinal scales can be median and other percentiles (Roberts, 1979; Stevens, 1946). These are reported in Figure 12 for the current edition and the past edition for comparing outcomes.

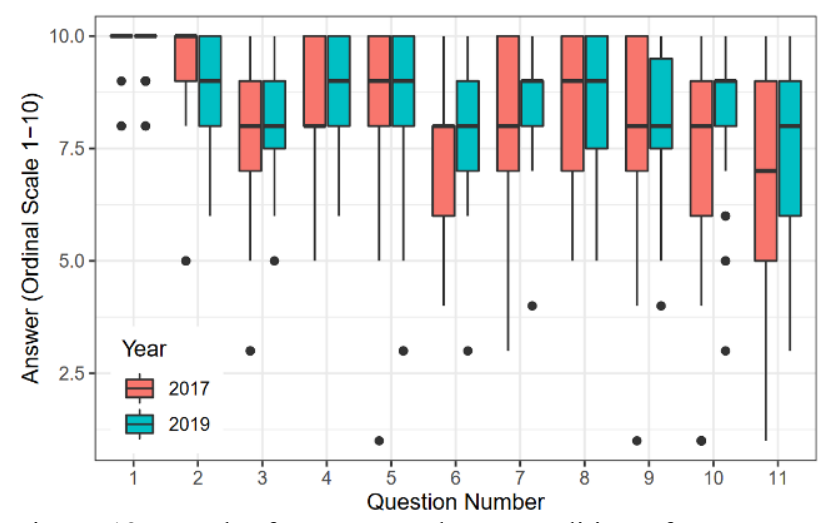

Figure 12. Results from past and recent edition of answers to questions with ordinal-scale answers $(10$ - high/good and 1 low/bad) - question number is related to enumeration in Table 4. Line represents median and box the interquartile range -25 th and 75 th percentile.

The distribution of answers to the first three questions shows that location, services and schedule are highly ranked by participants. Like in the previous edition, question 3, related to schedule, had a larger variance and is likely related to the feeling that more time is required for data analysis, as can be presumed by looking at 14 in the next section. 
Question 5,8 and 9 had one or two participants provide a score equal to 5 or lower. Questions 5 and 9 are questions related to schedule and workload respectively, which are always an issue in planning manifold activities that include fieldwork, data analysis, lectures, presentations and keynote speeches. Therefore, it can be expected that a small number of participants will struggle with the schedule and workload. Question 8 refers to the overall added value of the training, and one or two participants did not feel the activities added value to their knowledge-base, which could be compensated by providing additional modified i.e. advanced group work tasks if necessary. Question 11 also has some responses with lower votes denoting a mixed interest regarding following-up the work done at the summer school with a scientific publication. It can be noted that there were no significant shifts in results from the questionnaire between this and the past edition, showing an overall positive feedback in both cases, with all medians equal to or above eight.

3.2.2 Questions A-D: question A asked how participants learned about the summer school (Figure . It is interesting to note how things changed with respect to the 2017 edition; while most students proactively searched the internet for this kind of event in the past edition, in this edition more than half of participants learned about the summer school from other people in academia, colleagues or supervisors.

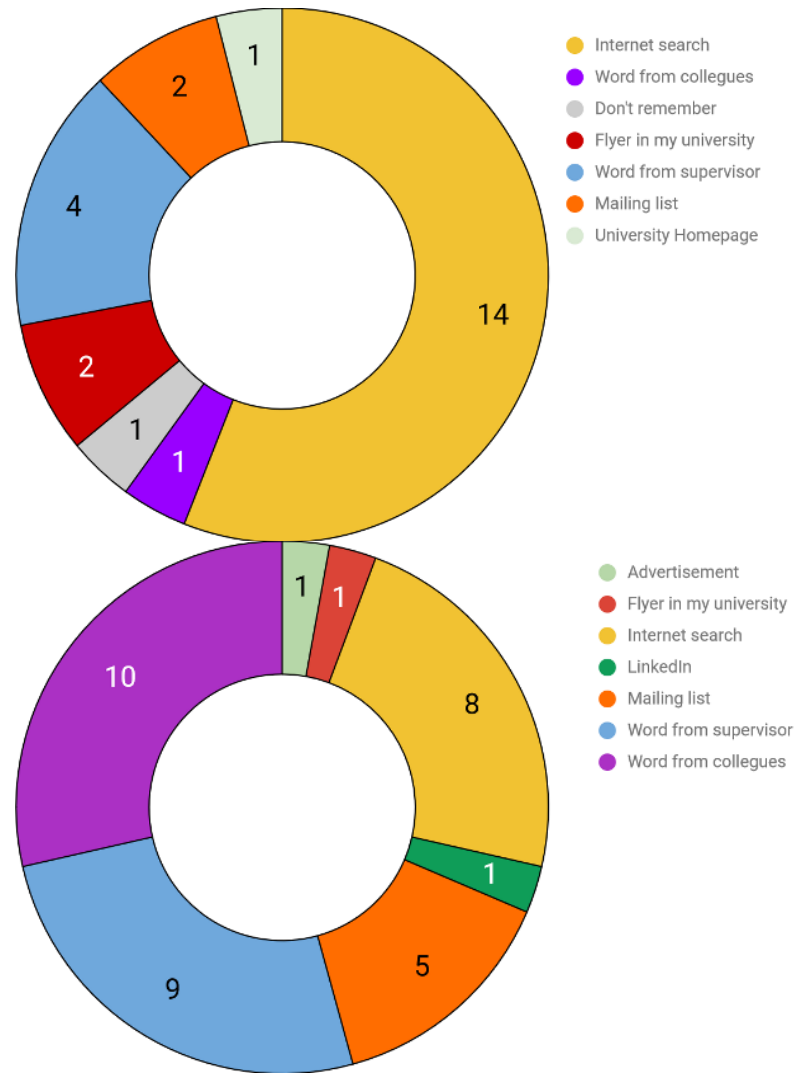

Figure 13. Distribution of how scholars learned about the summer school: from past 2017 edition (top) and 2019 edition (bottom).

The feedback regarding time assigned for different tasks (question B in Table 4) regarded four aspects of the activities, namely field work, assignment-related activity (data analysis), free time for networking and discussing and time for keynotes and lectures. Results reported in Figure 14 show an overall balance in the time schedule, except regarding fieldwork. This is probably due to some assignments, e.g. assignment 5 and 6 (terrestrial and UAV photogrammetry) having a large study area at one-hour walking distance. This required a significant amount of time and effort for reaching the area with equipment, setting up the area with ground targets and measuring them before the rest of the survey.

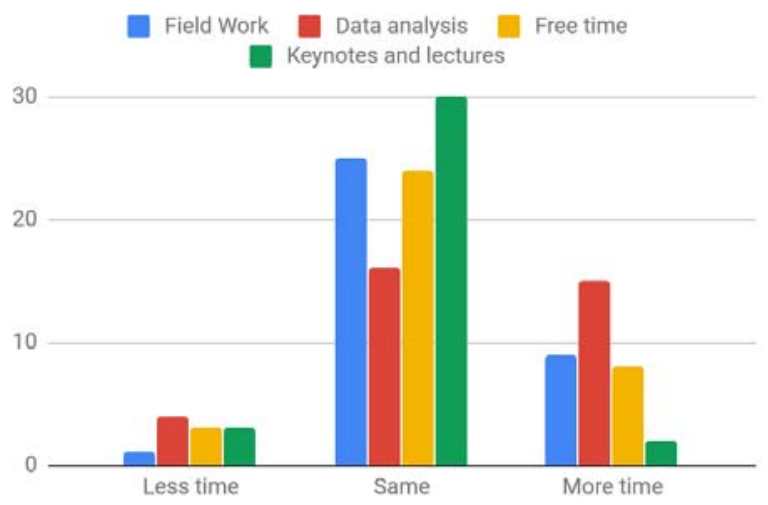

Figure 14. Participants' feedback on time schedule.

Regarding assignment selection, questions $\mathrm{C}$ and D ask what assignment was followed and which assignment was the first choice. As matter of fact all participants were asked to choose three of the seven possible assignments (see Table 2. Assignment topics) and rank them. The first choices were unbalanced as seen in Figure1515 and therefore ten students were given assignments that were either second or third choice.

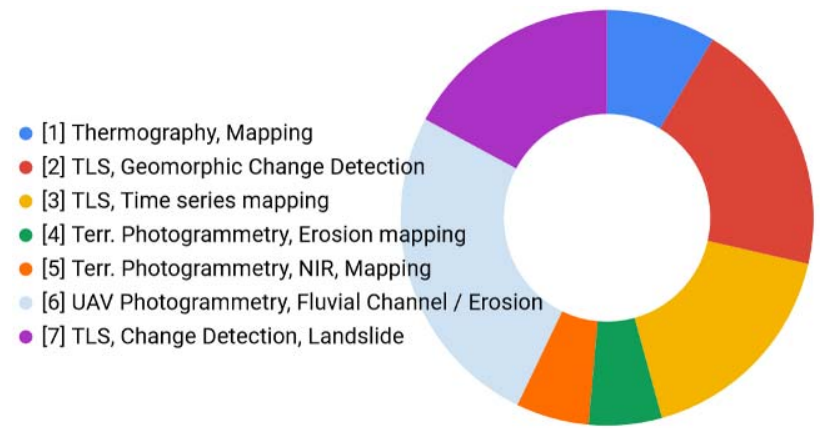

Figure15. Assignments with first choice by scholars.

3.2.3 Questions E-H: questions E through $\mathrm{H}$ have open answers, asking for positive or negative overall recommendations.

\section{CONCLUSIONS}

This article reported on the third edition of the international "Innsbruck Summer School of Alpine Research - Close-range Sensing Techniques in Alpine Terrain". Experiences from previous editions were elaborated upon to provide improvements on several aspects. Assignments provided a wide array of possibilities for trainees to learn on different aspect of Geomatics applied to mountain environments. The feedback mechanism that was created with a questionnaire provided insight on satisfaction of students and on possible improvements. When compared to the past edition, there was not a large significant change, maybe a bit of improvement with respect to the presence of lower votes (outliers). The overall success of the summer school confirms the ongoing demand for 
high-quality $\mathrm{PhD}$ training using close-range sensing technology in specific environmental monitoring setups.

\section{ACKNOWLEDGEMENTS}

The summer school organizing committee wants to thank all the sponsors, which are the Faculty of Geo- and Atmospheric Sciences and the Vice Rector for Research of the University of Innsbruck, University of Padova, and the Copernicus Academy. We further thank all keynote speakers, all supportive administrative staff from the University of Innsbruck and staff at the University Centre Obergurgl for hosting the event. We further thank the University of Innsbruck for funding data organisation and publication via Open Educational Data for Environmental Monitoring (OEDEM) and the ISPRS Education and Capacity Building Initiative for funding the online education project Spreading out the Knowledge from ISPRS Educational Events using a Dissemination Internet Platform (SKIEE-DIP).

\section{REFERENCES}

Axelsson, P., 2000. DEM generation from laser scanner data using adaptive TIN models, International Archives of Photogrammetry and Remote Sensing 33(B4/1; PART 4), 111118 .

Evans, J. S., Hudak, A. T., 2007. A Multiscale Curvature Algorithm for Classifying Discrete Return LiDAR in Forested Environments, IEEE Transactions on Geoscience and Remote Sensing 45(4), 1029-1038.

Fredembach, C., Süsstrunk, S., 2008. Colouring the NearInfrared. Final Progr. Proc. - IS T/SID Color Imaging Conf. 176-182.

Lindenbergh, R., \& Pietrzyk, P., 2015. Change detection and deformation analysis using static and mobile laser scanning. Applied Geomatics, 7(2), 65-74.

Lague, D., Brodu, N., and Leroux, J., 2013. Accurate 3D Comparison of Complex Topography with Terrestrial Laser Scanner: Application to the Rangitikei Canyon (N-Z). ISPRS Journal of Photogrammetry and Remote Sensing 82, 10-26. https://doi.org/10.1016/j.isprsjprs.2013.04.009.

Pfeiffer, J., Höfle, B., Hämmerle, M., Zahs, V., Rutzinger, M., Scaioni, M., Lindenbergh, R., Oude Elberink, S., Pirotti, F., Bremer, M., Wujanz, D., Zieher, T., 2019a. Terrestrial laser scanning data of the Äußeres Hochebenkar rock glacier close to Obergurgl, Austria acquired during the Innsbruck Summer School of Alpine Research. Institute of Geography, University of Innsbruck, PANGAEA, https://doi.org/10.1594/PANGAEA.902042.

Pfeiffer, J., Wujanz, D., Zieher, T., Rutzinger, M., Scaioni, M., Höfle, B., Lindenbergh, R., Oude Elberink, S., Pirotti, F., Bremer, M., Hämmerle, M., 2019b. Terrestrial laser scanning data of the Nesslrinna landslide close to Obergurgl, Austria acquired during the Innsbruck Summer School of Alpine Research. Institute of Geography, University of Innsbruck, PANGAEA,

https://doi.pangaea.de/10.1594/PANGAEA.901293.

Pfeiffer, J., Scaioni, M., Rutzinger, M., Adams, M., Graf, A., Sotier, B., Höfle, B., Lindenbergh, R., Oude Elberink, S., Pirotti, F., Bremer, M., Zieher, T., Hämmerle, M., Wujanz, D., 2019c. Terrestrial and unmanned aerial vehicle images of the Rotmoos valley bottom near Obergurgl, Austria with coordinates of corresponding ground control points acquired during the Innsbruck Summer School of Alpine Research 2015 and 2017. Institute of Geography, University of Innsbruck, PANGAEA, https://doi.org/10.1594/PANGAEA.898939.

Pirotti, F., Kobal, M., Roussel, J.R., 2017. A Comparison of Tree Segmentation Methods Using Very High Density Airborne Laser Scanner Data. Int. Arch. Photogramm. Remote Sens. Spat. Inf. Sci. XLII-2/W7, 285-290. https://doi.org/10.5194/isprs-archives-XLII-2-W7-285-2017.

Pirotti, F., Tonion, F., 2019. Classification of Aerial Laser Scanning Point Clouds Using Machine Learning: A Comparison Between Random Forest and Tensorflow. ISPRS Int. Arch. Photogramm. Remote Sens. Spat. Inf. Sci. XLII2/W13, 1105-1111. https://doi.org/10.5194/isprs-archivesXLII-2-W13-1105-2019.

Roberts, F.S., 1979. Measurement Theory with Applications to Decision Making, Utility, and the Social Sciences, Encyclopedia of Mathematics and its Applications.

Rutzinger, M., Bremer, M., Höfle, B., Hämmerle, M., Lindenbergh, R., Oude Elberink, S., Pirotti, F., Scaioni, M., Wujanz, D., Zieher, T., 2018. Training in Innovative Technologies for Close-Range Sensing in Alpine Terrain. ISPRS Ann. Photogramm. Remote Sens. Spat. Inf. Sci. IV-2, 239-246. https://doi.org/10.5194/isprs-annals-IV-2-239-2018.

Rutzinger, M. and Heinrich, K. (eds): Close Range Sensing Techniques in Alpine Terrain. Proceedings of the Innsbruck Summer School of Alpine Research 2019, 16.-22.06.2019 in Obergurgl, Austria. IGF-Forschungsberichte, 8, 2019. DOI: $10.1553 / \mathrm{IGF}-8$.

Rutzinger, M., Höfle, B., Lindenbergh, R., Oude Elberink, S., Pirotti, F., Sailer, R., Scaioni, M., Stötter, J., Wujanz, D., 2016. Close-Range Sensing Techniques in Alpine Terrain. ISPRS Ann. Photogramm. Remote Sens. Spat. Inf. Sci. III-6, 15-22. https://doi.org/10.5194/isprs-annals-III-6-15-2016.

Stevens, S.S., 1946. On the Theory of Scales of Measurement. Science 103, 677-680. https://doi.org/10.1126/science.103.2684.677.

Vos, S., Lindenbergh, R. and de Vries, S., 2017. Coastscan: Continuous monitoring of coastal change using terrestrial laser scanning. Proc. Coastal Dynamics 2017, Helsingor, Danmark, 12-16.

Zhang, W., Qi, J., Wan, P., Wang, H., Xie, D., Wang, X., Yan, G., 2016. An Easy-to-Use Airborne LiDAR Data Filtering Method Based on Cloth Simulation, Remote Sensing 8(6), 501. https://doi.org/10.3390/rs8060501

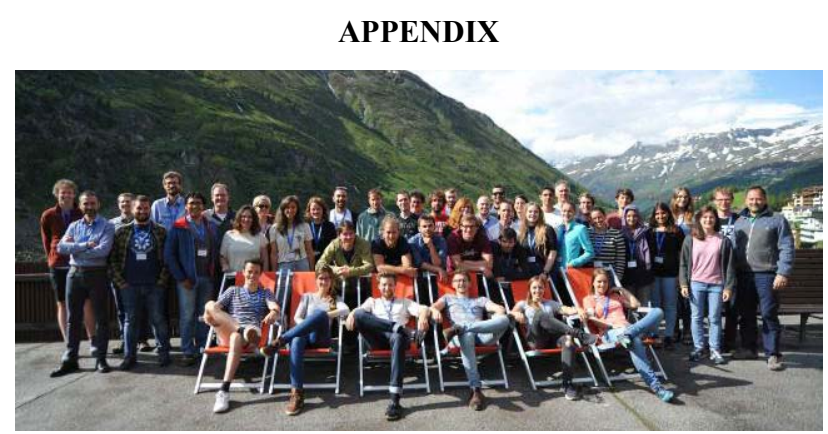

